\title{
Influence of Motivational Factors on Employees' Performance Case of Kenya Civil Aviation Authority
}

\author{
Benard Syengo Kilonzo Muli ${ }^{*} \quad$ Dr. Samson Nyang'au Paul ${ }^{2} \quad$ Dr. James Gitari Muriithi ${ }^{3}$ \\ 1.Department of Human Resource, Kenya Civil Aviation Authority, P.O. Box 30163 -00100 Nairobi, Kenya \\ 2.College of Human Resource Development, JKUAT, P.O. Box 62,000 - 00200 Nairobi, Kenya \\ 3.School of Business \& Economics ,CUK, P.O Box 24814-00502 Nairobi, Kenya
}

\begin{abstract}
In this 21 st Century Era organizations have appreciated that the throbbing heartbeat of the organization is in the workforce resource. Organizations are henceforth appreciating that it's of utmost necessity for employees and employers (management) to have a positive smooth relationship for a vibrant environment for growth to be experienced. This study was an assessment into the influence of motivational factors on employee performance in the Kenya Civil Aviation Authority. The researcher focused on training \& development, rewards management, employee relations and employee resourcing as the independent factors that employee performance depends on for good results to be achieved. The researcher dived in to this research because in this modern competitive era, business organizations are faced with ever-growing challenges regarding commitment, engagement, belief, recruitment and retention of their employees. Indeed multiple studies in different countries and across industries show that employees who are passionate about their jobs and the organizations in which they work are in the minority. The researcher enlisted the Maslow Hierarchy of Needs Theorem, the Mc Gregor Theory X and Y, the Vroom's Expectancy Theory and McClelland Human motivation theory in the Theoretical Review. Empirical review of the independent variables was also incorporated by the researcher though in a nutshell. Descriptive research design was adopted for this research. The researcher further used the two main methods of investigating and collecting data i.e. quantitative and qualitative. The target population of this study composed of all employees at the Kenya Civil Aviation Authority Headquarters in Nairobi City County of Kenya. Probabilistic sampling was used to determine the sample size. This study further adopted simple random sampling because the method is free of sampling error or classification error and it requires minimum advance knowledge of the population. Data in this study was collected from the two main sources namely; primary and secondary. Secondary data or desk research is the data from the internationally recognized news press, reports and periodicals. Primary sources are the major data sources. A questionnaire consisting of a number of questions was developed in a definite order on a form or set of forms. Further interviews were also conducted as source of primary data. For data organization the raw data collected was keyed into a spreadsheet and then copied in to Minitab. Analysis was done by use of statistical techniques; coefficient of correlation $(r)$ or simple correlation method which is the most widely used for measuring the degree of relationship between two variables qualitatively. Spreadsheets and Minitab 18 were used to facilitate analysis as they have in-built formulas. The researcher found out that reward management as variable was preferred by the employees when it was both monetary and non-monetary forms. In this state the significance level was found to be $84.9 \%$ towards the employee performance.
\end{abstract}

Keywords: performance appriasal, Rewarding, Employee Resourcing, Employee Relations

DOI: $10.7176 / \mathrm{EJBM} / 11-12-20$

Publication date: April $30^{\text {th }} 2019$

\section{Introduction}

Motivational theories help us to consider the different investments which can be made in people or the labour resource. Investment in workers through motivational measures are made today with the hope of future benefits for an organization. In a world characterized by competition, customer focus and the need for speed and flexibility, to get target results organizations still have to depend on people for success. With the global economy looking like it has returned to pre-recession levels, 2016 had brought with it a shift in emphasis. In recent HR Reflections surveys over half of organizations say their organizational performance is better than a year ago and that their focus is now on growth over recovery or stability. But with a healthier economy comes more mobility in the labour market. A quarter of global HR professionals said turnover is up in the year 2016 and $75 \%$ report difficulties in finding the right people. Indeed, talent attraction is the third greatest challenge facing HR professionals this year ( ORC International, 2016). In deed the researcher will review the year 2017 report once out to check whether the same trend proceeds or has been mitigated, as comparing year 2015 to year 2016 the trend proceeded to the worst with minimal improvement. Globally talent attraction isn't the only issue. Engaging employees is an increasing problem for organizations. Turnover is up, essential skills remain elusive, multi-generation workplaces are the new norm and a technology-obsessed world has created opportunities and demand for a variety of new working set ups, ergo employers have a lot to deal with. How organizations engage their employees under these evolving conditions goes some way to identifying who wins the war for the best talent. A strong and effective leadership has never 
been more important to guide the way and provide focus in this time of flux. But the development of leaders is the number one headache for HR professionals ( ORC International, 2016). With at least three generations of employees co-existing in most workplaces, managing differing and often conflicting needs is a major organizational challenge. In the $2014 \mathrm{HR}$ Reflections survey ORC International found that $74 \%$ of $\mathrm{HR}$ professionals believe Millennia's are different to the generations that precede them and 62\% report difficulty in retaining them. Understanding the views different generations have of the employee experience and what motivates each group is a first step to making that challenge a little easier.

\subsection{Employee Performance}

Over the past decade, and particularly in the past three years, employers and employees have faced human capital challenges and an uncertain economy. The economic downturn that started in 2008 has had a significant impact on companies and the resulting decisions made by management. These decisions have impacted employee performance levels and perceptions globally, leading to changes in leading drivers of employee performance engagement. In uncertain times, organizations need to focus on harnessing the discretionary effort that engaged employees deliver. This makes the difference in how companies are affected during the economic downturn, how quickly they emerge from it, and how strong they are in the future after the downturn passes (AON, 2011). The 2017 Trends in Global Employee Engagement Survey noted that 2017 was much better in terms of growth in Africa; however it was noted that organizations should be prepared for the lagged effect between 2016 economic forces and 2017 employee performance and engagement. The survey further asserts that a holistic talent, reward and performance strategy should be the bedrock of any organization aiming at making Africa an important part of its future growth strategy.

The only way to get employees work hard and perform effectively is to motivate them. Every employee in an organization is motivated in different ways. Everyone works on a theory of motivation, what drives a person or organization to make the choices that they make. Without any kind of motivation or direction, a business or organization will not have a direction and are potentially in threat of losing business or worse. As organizations are characterized by employees, it is therefore necessary to put in place motivational systems that will be a vital factor for employee performance and the achievement of the organizational goals and objectives (Robbins, 2005).

\subsection{Statement of the Problem}

Enterprises are facing ever-growing challenges on routinely regarding commitment, engagement, recruitment and retention of their employees. Multiple studies in different countries and across industries show that employees who are passionate about their jobs and the organizations in which they work are in the minority. (DDI, 2017) own research reveals that only 19 percent of employees are highly engaged within their organization. The number of employer's experiencing retention difficulties has climbed from $69 \%$ in last year's (2016) survey to $78 \%$ in this year's (2017) survey. Private sector firms claim to be struggling more to hold on to employees than any of the other sectors $(83 \%)$ in the economy globally these is mostly attributed to lack of motivated workforce. With workplaces evolving in line with advances in technology and in response to the competing needs of different generations, engagement as a concept has had to evolve too. It is no longer always sufficient to have a workforce that just says, stays and strives. Firms need to take into account the sustainability of that workforce; ensure our workplaces are representative of the wider marketplace profile and that these diverse views, experiences and skills are respected and considered; and we need to have confident employees who are motivated and empowered to think creatively and constantly look for new and better ways of working. With these needs comes an enhanced model of engagement that incorporates sustainability, creativity and inclusivity (Humanity, 2016) The object and purpose for which the Authority was established is to plan, develop, manage, regulate and operate a safe, economical, and efficient civil aviation system in Kenya in accordance with the provisions of the Civil Aviation Act. With this delicate mandate satisfied and motivated employees would be critical to help build a strong experienced team. The researcher conducted the research at KCAA to assess on the impact of catalyzed motivation on employee performance. KCAA was chosen as the organization for study because its core mandate is quite delicate and a lapse of employee performance could cause calamities in both short and long-term for the economic wellness of the country. The Authority has experienced staff turnover, longevity in promotion of experienced employees due for promotions or working in acting capacity and lack of employee clear future employee growth policy.

\subsection{Training and Development on Employee Performance}

Staff training and development significantly affect the financial and non-financial performance of the organizations. Two hypotheses were tested and the findings indicate that there is a positive relationship between training/staff development and financial performance of Islamic financial institutions. Also, the results from the data analysis indicated that significant relationship exist between training/staff development and non-financial performance of Islamic financial institutions (Muhabit \& Taminayu, 2016). Neelam (2014), research on the impact 
of training and development on employees' performance and productivity found significant relationship existed between training/staff development and employee performance. He applied regression analysis on the collected data and used 0.05 level of significance. Sultana. A, et.al. (2012), study conducted in telecom sector of Pakistan, states the $\mathrm{R}^{2}$ as .501 which means that $50.1 \%$ of variation in employee performance is brought by training programs. Further, the T-value was 8.58 that explain training is good predictor of employee performance. As depicted by the work of Harrison (2000), learning through training influence the organizational performance by greater employee performance, and is said to be a key factor in the achievement of corporate goals. However, implementing training programs as a solution to covering performance issues such as filling the gap between the standard andthe actual performance is an effective way of improving employee performance (Swart et al., 2005). According to Swart et al., (2005), bridging the performance gap refers to implementing a relevant training intervention for the sake of developing particular skills and abilities of the workers and enhancing employee performance. He further elaborate the concept by stating that training facilitate organization to recognize that its workers are not performing well and a thus their knowledge, skills and attitudes needs to be molded according to the firm needs. There might be various reasons for poor performance of the employees such as workers may not feel motivated anymore to use their competencies, or maybe not confident enough on their capabilities, or they may be facing work- life conflict.

\subsection{Reward Management and Employee Performance}

Rewarding can be linked to extrinsic and intrinsic motivation. This extrinsic motivation is induced by external factors which are primarily financial in nature while the converse is intrinsic. The incentives and reward has been a subject of debate, whether they really motivate the employees or simply move them to work. According to Ryan and Deci, (2012), the term, "extrinsic motivation" is the attainment of a separate outcome from the performance of an activity. Extrinsic motivation encourages staff to complete their task in order to receive the reward. They opined that the overall strategic aim of reward system management is to develop and implement the reward policies, processes and practices required to support the achievement of organizational goals by helping to ensure that it has the skilled, competent, well-motivated and committed people it needs. The philosophy underpinning the strategy is that people should be rewarded for the value they created. The objective is therefore to create reward processes that are based on beliefs about what the organizational values prepared to pay for (Mintzberg, 2011).

\subsection{Employee Relations and Employee Performance}

Shazhad (2013) study on whether Employee Relations Practices Impact on Performance of Employees working in Hospitality Industry of Pakistan found out that they significantly related. There appears to be a consensus that employee relations continues to be a critical area for HR to manage. Some respondents claimed that large employers need representative structures in order to be able to communicate effectively with their employees. Though not a universal belief, research and other evidence suggests that many larger employers in both the public and private sectors accept this and are concerned to maintain or, if necessary, establish effective machinery for consulting employees. Within the public sector, some respondents displayed a strong commitment to working in partnership with their trade unions and this was reflected in both formal and informal contacts and committee structures (CIPD, 2016). The general view was that organizations needed to be capable of dealing with employees on both an individual and a representative basis. In terms of what actually needs to be managed, the emphasis was not so much on pay but on issues such as recruitment, retention, and pensions. Many respondents also underlined the need to be able to anticipate as well as respond to employment law. And finally, there was strong endorsement from several respondents of the belief that employee relations is about seeing the 'big picture' and helping the organization to take appropriate action. The most detailed and persuasive responses reflected a view that effective employee relations practitioners were strong at storytelling and making sense of situations: ensuring that organizations told a consistent and credible story. This could be seen as one interpretation of 'strategic HR' (CIPD, 2016)

\subsection{Employee Resourcing and Employee Performance}

Sully (2016) Effective employee resourcing strategies allow organizations, and the individuals and groups within them, to achieve mutually beneficial objectives. These approaches consist of the need for consistency across resourcing practice and the significance of the devolution of HRM activity to line management. The suite of resourcing practices needs to be, from a strategic perspective, interlinked and mutually reinforcing. Thus, recruitment and selection practices need to emphasize those core attributes and values that define the business and its purpose. The assessment techniques that are used in selection reflect these attributes, in terms of both what is assessed and how it is done. Induction further reinforces those values that are central to shaping performance management efforts within the business. Similarly, reward strategies support the application and demonstration of those attributes and communicate consistent messages about what the organization values. Changes to core values can be communicated and reinforced through these same resourcing activities. It's however not sufficient simply 
to develop strategy and policy and hope this will result in strategic integration. Regarding devolution of HRM activity to the line management, the ongoing enactment of such policies and practices through line management are the test by which their success is evaluated. Such devolution of responsibility requires continuous reinforcement and systems that support, rather than undermine, policy. Enabling line management to recognize and take responsibility for HR activity represents one of the shifts in the role of the HR specialist, leading such developments and influencing organizational practice as a whole.

\subsection{Research Gaps}

A significant amount of research has been conducted within the field of employee motivation, although the rate of progress has been stagnant since the late 1970s. Organizations' and researchers current comprehension of employee motivation is by no means complete most of all in this $21^{\text {st }}$ century. Thus, a lot remain to be uncovered in order for managers to fully understand how to motivate the employees in an effective manner. Further, motivation is a continuously changing phenomenon which requires constant exploration as well as organizational adaption, due to the fact that the core generations of employees have changed overtime. The intensified competition has instigated a shift that requires organizations to compete in new and innovative ways, one alternative is to regard valuable human capital as a competitive advantage rather than as a renewable resource, which is the traditional view (DDI, 2017). Thus, a high degree of employee motivation is an effective tactic to retain highly skilled individuals, further motivational research should be conducted within facilities where the work tasks are commonly static and uninteresting, which means that the managers must uncover alternative solutions to enhancing the workers level of motivation. Further studies that explores the motivational circumstances differ significantly based on the organizations economic activity as well as industry, as well as exposure to technological advancement. Some employees who have technological expertise would be better motivated (Rainey, 2009). Most of the motivational models used today were developed in earlier eras when both the work environment and employees were totally different. There thus exist a gap of developing new models or improving the current ones to ensure that they incorporate the current change and developments in the workplace interactions (Ivy Business, 2018). HBR (2018) in a study frontline management operating model focused on optimizing play, purpose, and potential while reducing the pressure. Reduction of the economic and emotional pressure; which ensured that the employees who are frontline of the company could focus on learning, highpressure motivation tactics, including sales commissions, high-pressure conversations, sales-based promotion criteria, and public shaming were to be eliminated. Leaders got the explanation that great leadership isn't about pressuring people to do their work. Rather, it is about inspiring your people to want to do their work well, so they can perform adaptively. This model needs to be researched in more industrial setting including public institutions as this was only done in a retail sector. Mercer, a leading global provider of consulting, outsourcing and investment services issued a report showing that the "reward perception gap' between employers and employees is eroding employee engagement levels and threatening company productivity and economic recovery. According to the report, the majority of employees felt their reward levels were below average compared to what they might have received at rival organizations. This contrasted with employers who felt that their employees' reward levels are competitive or above average. This shows that a gap exist in research as a study could be done to ascertain why most employers have the perception that the employee requires monetary rewards upwards to motivate them.Public servants motivation has long been a topic of concern, debacle and scholarly interest. In Kenya there is no referenced literature on this issue. Recent occurrences give the topic prominence .One is the global public management revolution (Kettle, 2005) driven by governments search for continuously higher levels of productivity, service orientation and accountability. Another development being the consistent failure of financial incentives schemes (Perry, Mesch and Paarlberg, 2006) that were adapted from the private sector beginning in the late 1970's. A third development, given the impetus by the first two is increasing attention to the merits of bureaucracy as an institution and a normative order (Olsen, 2006). The intersection of these developments helps account for growth of scholarly interest in public service motivation. A long standing research problem about motivation is that it has been concentrated on Industrial and business organization (Perry \& Porter, 1982; Kelman 2005) hence a research gap exist.

\subsection{Target Population}

The target population of this study composed of all employees at the Kenya Civil Aviation Authority Headquarters in Nairobi City County of Kenya. This was a total of about 700 employees in the 3 major directorates of the KCAA which include, DAASR which has 7 departments, ANS which has 3 departments and CD which has 8 departments which represents a $100 \%$ of the population.

\subsection{Sampling Design}

This study adopted simple random sampling because the method is free of sampling error or classification error and it requires minimum advance knowledge of the population. For these reasons, simple random sampling best 
suits situations where not much information is available about the population and data collection can be efficiently conducted on randomly distributed items, or where the cost of sampling is small. Further Stratified sampling was used because the population of interest is heterogeneous. There should be an adequate proportion as a representative sample of at least be $10 \%$ of the total target population for adequate results to be achieved (Mugenda \& Mugenda, 2009).

Table: 3.1

The Target population and Sample Size

\begin{tabular}{cllcc}
\hline Scales/Grades & Category & Population & Sample Size & Percentage \% \\
\hline $1,2,3$ & Directors \& Deputies & 6 & 2 & $33 \%$ \\
4,5 & Managers & 24 & 9 & $38 \%$ \\
$6,7,8$ & Chiefs, Senior \& Officer 1 & 70 & 25 & $35 \%$ \\
9 & Officer II & 100 & 35 & $35 \%$ \\
10 & Officer III & 150 & 45 & $30 \%$ \\
$11,12,13,14$ & Clerical \& Support Staff & 350 & 125 & $36 \%$ \\
& & $\mathbf{7 0 0}$ & $\mathbf{2 4 1}$ & $\mathbf{3 4 \%}$ \\
\hline
\end{tabular}

\subsection{Data Collection Instruments}

Data in this study was collected from the two main sources namely; primary and secondary. Secondary data or desk research is the data from the internationally recognized news press, reports and periodicals. Primary sources were the major data sources. A questionnaire consisting of a number of questions was printed and typed in a definite order on a form or set of forms. The questionnaires were dropped and collected from respondents who were expected to read and understand the questions and write down the reply in the space meant for the purpose in the questionnaire itself. The respondents had to answer the questions on their own (Kothari, 2004). The primary data was obtained through self-administered questionnaires and personal interviews which were both structured and unstructured. The questionnaires were constructed to cover the key research queries of this study. The advantages of a questionnaire over other instruments include, information can be collected from large samples, no opportunity for bias since it is presented in paper form, confidentiality is upheld, and it saves on time. Interviews were conducted with the key employees within the selected sample size. This method involved contact between the researcher and respondents (key employees).

\subsection{Data analysis and Presentation}

After data organization, analysis was done by using statistical techniques; coefficient of correlation $(r)$ or simple correlation method which is the most widely used for measuring the degree of relationship between two variables qualitatively. Spreadsheets and Minitab 18 were used to facilitate analysis as they have in-built formulas. Minitab is a comprehensive system for data analysis and can take data from any type of file and use it to generate tabulated reports, charts, compare means, correlation and many other techniques of data analysis (Microsoft, 2010). These packages were used to carry out descriptive statistics like the measures of central tendency, extract frequency graphs and tables. Run tests of hypothesis like ANOVA and carry out a correlation and regression analysis where applicable. Correlation measures the extent of interdependence where two variables are linearly related (Lucy, 1996). If variables are correlated then a change in one variable is accompanied by a proportionate change in another variable.. However, with the help of the Minitab software results for the above statistical tests were automatically computed and generated in tabular form. Ratio analysis was also be used to test if there has been change employee performance before and after motivation techniques implementation. With the help of ratio analysis a company may have comparative study of its performance to the previous years (Gupta, 2005). In this way firms can realize on their weak points when managing the human resource and improve on them. The data collected and analyzed will be presented using appropriate frequencies, bar graphs and pie charts to provide a clear show of how motivation stimulates high employee performance. Regression analysis is a form of predictive modelling technique which investigates the relationship between a dependent (target) and independent variable (s) (predictor). This technique is used for forecasting, time series modelling and finding the causal effect relationship between the variables (Vidhya, 2007). Multiple regression analysis can be used to assess whether confounding exists, and, since it allows us to estimate the association between a given independent variable and the outcome holding all other variables constant, multiple linear regression also provides a way of adjusting for potentially confounding variables that have been included in the model. The researcher thus adopted it in regressing the variables to ensure he gets the relationship between the two. Therefore, Employee performance is our criterion (or dependent variable). Training \& Development, Reward Management, Employee Relations and Employee Resourcing are our predictors (or independent variables). It should be kept in mind that regression is not to prove any causal relations from our predictors on employee performance. Regression model shows the mathematical relationship between the independent variable strategic knowledge management practices and dependent variable organizational innovation. 
$\mathbf{Y}=\boldsymbol{\beta}_{0}+\boldsymbol{\beta}_{1} \mathbf{X}_{1}+\boldsymbol{\beta}_{2} \mathbf{X}_{2}+\boldsymbol{\beta}_{3} \mathbf{X}_{3}+\boldsymbol{\beta}_{4} \mathbf{X}_{4}+e$

4.0 Regression Analysis

Model Summary

\begin{tabular}{lll}
\hline Model & R & $\mathbf{R}^{2}$ \\
\hline 1 & $\mathbf{0 . 6 9 7}$ & $\mathbf{0 . 4 8 6}$ \\
\hline
\end{tabular}

Table 4.23

Model Co-efficient.

\begin{tabular}{lll}
\hline Independent Variables & Co-efficient $(\beta)$ & Sig. \\
\hline 1. (Constant) & 0.682 & 0.000 \\
Reward Management & 0.849 & 0.000 \\
Training \& Development & 0.07 & 0.367 \\
Employee Relations & 0.256 & 0.002 \\
Employee Resourcing & 0.194 & 0.030 \\
\hline
\end{tabular}

The regression equation is therefore:-

$\mathrm{Y}=\mathrm{a}+\mathrm{b}_{1} \mathrm{x}_{1}+\mathrm{b}_{2} \mathrm{x}_{2}+\mathrm{b}_{3} \mathrm{x}_{3}+\mathrm{b}_{4} \mathrm{X}_{4}$.

a: Represents dependent variable which is Employee Performance

$\mathrm{R}$ : Represent the relationship between dependent and all the independent variables.

$\mathrm{R}^{2}$ : Represent how much of the depend variable can be explained by the independent variable

$B$ Represent co-efficient of the independent variable

Sig. Represent the statistical significant level of the model.

When the values from the table are computed, the equation becomes $\mathrm{Y}=0.682+0.849\left(\mathrm{x}_{1}\right)+0.070\left(\mathrm{x}_{2}\right)+$ $0.256\left(\mathrm{x}_{3}\right)+0.194\left(\mathrm{x}_{4}\right)$. From the equation, it was realized that motivation had a catalytic relationship with employee performance. There was a correlation value was 0.697 which is considered a moderate as it falls between 0.30 and 0.80 (Pallant, 2011). The positive value indicated that, there was a positive correlation between the independent and dependent variables. The $\mathrm{R}_{2}$ proves $48.6 \%(0.486)$ of employee performance could be explained using the independent variables. From the regression the co-efficient value for reward management in the authority was 0.849 . This means all other factors held constant then performance would increase by $84.9 \%$ if there is $100 \%$ improvement in reward management and execution. This meant that the variable (reward management) was statistically significant and was making a significant unique contribution to the prediction of the dependent variable (employees' performance). The respondent's employees were of the view that rewarding and its effective management is a strong factor that motivates them and should be reviewed from time to time to help align with the changing cost of living. From the regression the co-efficient value for training and development was 0.070 . This means that all things constant, performance would increase by $7 \%$ if there is $100 \%$ improvement in training and development.

\subsection{Summary}

This study sought to examine whether motivation was a catalyst for employee performance. It focus study organization was the civil aviation authority of Kenya. This was achieved via answering the specific objectives; to examine if reward management influence employee performance, to assess if training and development is an enhancer of employee performance, to explore the extent to which employee relations stimulate employee performance and to examine if employee resourcing is a catalyst for employee performance. The data analysis multiple regression analysis guided by the research questions that were in reference to study objectives. From the study it emerged majorly that $63 \%$ respondents were male, $58 \%$ were of ages between $31-50$ Years, had served the company for six to ten years $32 \%$. It was further noted that majority of respondents $41 \%$ had a college diploma /certificate. The minority of the respondents were female at $37 \%$.

\subsection{Recommendations}

Based on the findings of this study the researcher can suggest some recommendations for both practitioners and researchers. Managers in the Kenyan firms need to find ways to motivate and retain employees and increase their performance. Otherwise, they will discover they are losing their talented and creative workers to other organizations who are more prepared and willing to meet their needs and demands. The psychological contract/undeclared expectations of both parties' employees and organization need to be explored through surveys and interview. Moreover, organizations must understand that employees' work outcomes are influenced by their levels of motivation and satisfaction. And that motivated and satisfied employee are the right people that they need to get the things done right and efficiently. Opening dialogue is very essential to bridge gaps in expectations through developing and conducting satisfaction and motivation surveys routinely. 


\subsection{Suggestions for Further Research/Studies}

Future research may be carried out to examine the role of perceived work motivation in mediating the link between workforce satisfaction and performance. Unlike previous studies, the current study suggests that satisfied employees are likely to be more motivated to produce. Further research is needed also needed to explore the role of work force/employee satisfaction in predicting work motivation in order to reach more general understanding across cultures about the links between motivation and performance.

Further research could be carried out within the public service so as to examine if there is a link between employee motivation and corruption in Kenya. This study thought is contributed by the fact that in the current Era of our economic and political dispensation huge infrastructural projects are being launched and every time they are encumbered by corruption.

\subsection{Knowledge Learnt}

After a long career in the public service as a human resource professional driven by passion to ensure that government institutions works both national and county and in pursuit of the master degree leading to this specific study has made me reflect on a number of issue in the public service human resource management that require adequate improvement both in policy and physical. This would be necessitated because as the global environment becomes more complex and interpersonal interactions are increasingly limited due to new technologies, the human element of the public sector workforce continues to fascinate and inspire further inquiry as productivity and performance drop as well as increase corruption rates. Having had the opportunity to work with all four generations in the public workplace, I continue to be amazed by their dedication and service. Government policy makers and implementers need to be qualified in the areas of appointment rather than being politically correct so as to be able to rekindle motivation among employees in the public sector which will thus lead to increased productivity and performance among employees.

\section{References}

AAPOR, (2011), America Association for Public Opinion Research, 111 Deer Lake Road, Suite 100, Deerfield USA.

Amabile, T. (2003).Motivational Synergy: Toward New Conceptualizations of Intrinsic and Extrinsic Motivation in the Workplace. Human Resource Management Review, (3), 185-201.

AON ( 2016). 2016 Trends on Global Employee Engagements, AON Minet Publications.

Armstrong, M. (2012).A Hand Book of Human Resources Management Practice (12 ${ }^{\text {th }}$ Ed.)

Azoulay, P; Joshua, S; Graff, Z \& Manso, G. (2011) "Incentives and Creativity: Evidence from the Academic Life Sciences." RAND Journal of Economics, 42.3 (Fall 2011), pp. 527-554.

Beardwell, J (2009). Human Resources Management a contemporary Approach (6 ${ }^{\text {th }}$ Ed.)

Brown, K.(2017). Formative evaluation: An integrative model and case study. Personnel Psychology, "Evaluation of Management Programs. An innovative approach". Human Resource Management Review, (5), 105-110

Bowen, B; \& Radhakrishna, B (1991). Job Satisfaction of Agricultural Education Faculty: A Constant Phenomena. Journal of Agricultural Education, 32(2), 16-22.

Boree, G. (2006). The Ultimate Theory of Personality. Webspace. Ship.Edu

Boxall, P. \& Purcell, J. (2011). Strategy and Human Resource Management. 3rd edn. China: Palgrave ... Management, 53(3), pp. 245-260. UK: Palgrave Macmillan.

Boyle, R. (2012).Public Service Trends 2012. Dublin: Institute of Public Administration

Bryman, A. \& Bell, E. (2011). Business Research Methods. $3^{\text {rd }}$.Ed: Oxford University Press. 765.

CIPD, (2016). "Qualitative and Quantitative review on employee motivation and performance Approaches", CIPD Publications, INC.

Creswell, J. (2009). Research Design: Qualitative, Quantitative and Mixed Methods Approaches $3^{\text {rd }}$ Ed, California, SAGE Publications, INC.

Cooper, G. (2006). Subliminal Motivation: A Story Revisited. Journal of Applied Social Psychology. 32(11):2213 $-2227$

Dicicco-Bloom, B. and Crabtree,F. (2006) The Qualitative Research Interview. Journal of Medical Education, 40, 314-321.

DDI, (2017). Qualitative analysis of workplace trends on employee engagement 2017 Development Dimensions Publications.

Elder, F. \& Manso, G. (2011). “Is Pay for Performance Detrimental to Innovation?” Journal of Applied Sciences, $50,317-328$.

Greenberg, J. \& Baron, A.R. (2003). Organizational Behaviour in Organization. Understanding and Managing the human side of work. Canada: $8^{\text {th }}$ Ed, Prentice-Hall, Upper Saddle River 
Falola, H. (2014). "Effectiveness of Training \& Development on Employees Performance and Organization Competitiveness in the Nigerian Banking Industry." Research Gate. 30, 315-326.

Forgas, J. (2005). Social Motivation. Conscious and Unconscious Processes. Cambridge. Cambridge University Press. 386.

Humanity, (2016). "Human Motivation as an effective tool for Organizational Growth”, Humanity Pty Publications.

Kothari,C.R.(2004).Research Methodology,Methods\&Techniques. New Age International (P) Limited Publishers, $3^{\text {rd }}$ Ed, New Delhi.

Latham, G.(2007). Human Resources Management (International Edition ed.). (9 ${ }^{\text {th }}$, Ed.) Prentice Hall.

Lazonick, W. (2014). "Purposeful Development, Customer First and Motivation". The Academic Industry Research Network.

Lindner, K. (2008). Privatization of Public Services. "Impact for Employment and Working Conditions". (5 $5^{\text {th }}$ Ed) Hall. Inc.

Lucy, T. (2006). The influence of individual characteristics and work environment on varying levels of training outcome. Human Resources Development Quarterly.

Mugenda, A. \& Mugenda, O. (2009) Research Methods: Quantitative and Qualitative Approaches. American Journal of Educational Research. Vol. 4 No 123-230. 